\title{
Local Heat Transfer Coefficient Measurements on an Engine Representative Internal Cooling Passage
}

\author{
Joshua R. Ryley*, Matthew McGilvray ${ }^{\dagger}$ and David Gillespie ${ }^{\ddagger}$ \\ University of Oxford, Oxford, United Kingdom, OX1 3PJ
}

\begin{abstract}
Spatially resolved heat transfer measurements of turbomachinery components can lead to more accurate metal temperature distributions, leading to better predictions of thermal stresses in the blade and ultimately blade life. The increased fidelity of the spatially resolved data also provides a dataset which can delineate the complex fluid and heat transfer processes for the purpose of numerical validation. This research applies transient liquid crystal experiments on stationary engine representative internal cooling passages with a filleted rectangular cross-section and staggered $45^{\circ}$ ribs on two opposing walls. The ribs have a rounded profile and span half the width of the passage. Pressure loss measurements and spatially resolved heat transfer coefficients have been collected over the full surface of the test section over a range of Reynolds numbers $(18,000-105,000)$ for three aspect ratios $(1: 2$, 1:3 and 1:4). The experimental results were compared to widely used empirical correlations for ribbed passages with full width ribs in sharp-cornered passages. The average Nusselt number and friction factor differed from industry standard correlations by a maximum of $45 \%$ and $10 \%$ respectively.
\end{abstract}

\footnotetext{
${ }^{*}$ DPhil, Department of Engineering Sciences, Parks Rd Oxford, joshryley@gmail .com

${ }^{\dagger}$ Associate Professor, Department of Engineering Sciences, Parks Rd Oxford, matthew.mcgilvray@eng.ox.ac.uk

\#Associate Professor, Department of Engineering Sciences, Parks Rd Oxford, david.gillespiedeng.ox.ac.uk
} 


\section{Nomenclature}

\section{Symbols}

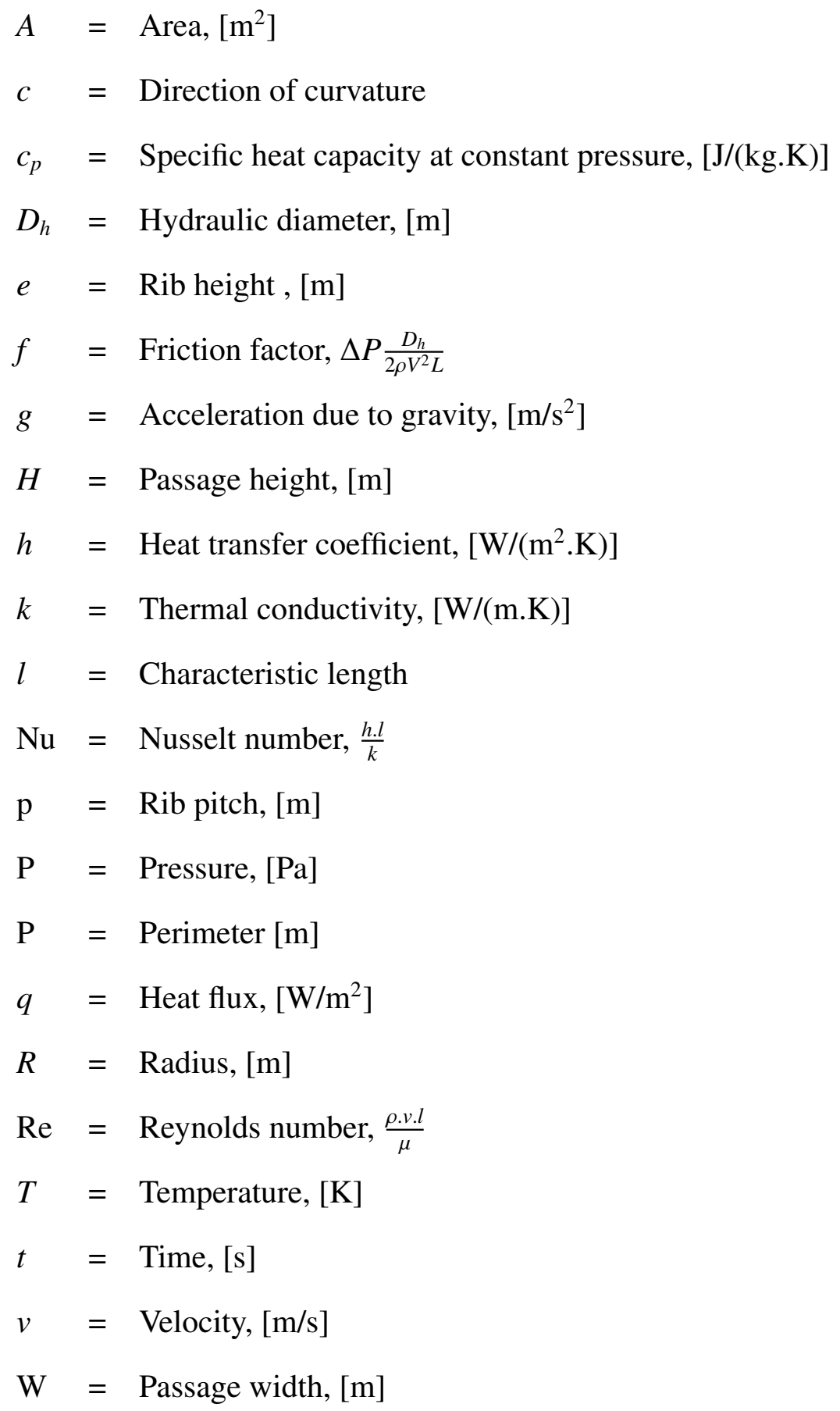




\section{Subscripts}

$\begin{array}{ll}\mathrm{g} & =\text { Gas } \\ \mathrm{i} & =\text { Initial } \\ 0 & =\text { Reference } \\ f p & =\text { Flat plate } \\ r & =\text { Radial corrected } \\ \mathrm{s} & =\text { Surface } \\ x & =\text { Cross-section }\end{array}$

\section{Greek}

$$
\begin{array}{ll}
\alpha & =\text { Rib angle, }\left[^{\circ}\right] \\
\beta & =\text { Equation } 2 \\
\theta & =\text { Non-dimensional surface temperature } \\
\mu & =\text { Dynamic viscosity, }[\text { Pa.s }] \\
\rho & =\text { Density, }\left[\mathrm{kg} / \mathrm{m}^{3}\right]
\end{array}
$$

\section{Abbreviations}

AR $=$ Aspect Ratio, $(\mathrm{W} / \mathrm{H})$

ERICKA $=$ Engine Realistic Internal Cooling Knowledge Applications

HTC $=$ Heat Transfer Coefficient

LE $\quad=$ Leading Edge

PS $\quad=$ Pressure Side

SS $\quad=$ Suction Side

$\mathrm{TE} \quad=$ Trailing Edge

THTAC $=$ Transient Heat Transfer Analysis Code

\section{Introduction}

The continued drive to increase engine efficiency, in order to lower fuel consumption and environmental impact, has led to a rise in the turbine entry temperature. Raising this further is constrained by the high pressure turbine blade and vane material temperatures, where it has been speculated 
that a $10-15 \mathrm{~K}$ rise in component temperature may reduce blade life by half $[1,2]$. Improvements in the design of HP turbine blade internal cooling system, whilst maintaining component life, would allow for an increase in gas temperature and/or a reduction in coolant mass flow rate; ultimately, both result in a reduction of specific fuel consumption.

Existing technology used in mid-chord internal cooling passages is primarily based around rib turbulators. This allows long passages to be employed which exploit the full temperature potential of the coolant, prior to ejection as a coolant film. There is a large body of research in this field investigating how various geometric factors influence heat transfer and pressure drop, with notable use made industrially of the work by Han and his colleagues [3,4]. Data from these studies have been collated in empirical formulas and are used in developing designs of internal cooling passages, a common industry practice [5].

Numerical simulations (CFD) are commonly used to investigate component design, and are compared to existing experimental data for validation. Many different methodologies are employed for such comparisons [5-7]. In the open literature there is no comparison that demonstrates which method is most effective. The majority of the methods compare bulk heat transfer coefficient (HTC) values and, in doing so, fail to evaluate whether detailed features are captured. This limitation is highlighted in numerical optimisation schemes, which given a set of constraints, look for a design with the best performance. This requires that the heat transfer distributions in the passage are accurately modelled. If numerical results are validated only against an area averaged value, without considering the accuracy of the trends in heat transfer, this could potentially lead to false results when optimising.

Experimental investigations conducted in this field have tended to focus on highly idealised geometries, with sharp edged ribs and passages. A more engine representative passage may contain additional features, such as: filleted ribs, which may not extend across the full width of the passage, a non-rectangular and/or variable passage cross-section, and the presence of film-cooling bleed holes. Schüler et al. [8] highlighted the need for investigations into engine representative geometries, in order to capture flow pattern characteristics, whilst remaining sufficiently generic to allow wide application of the results. Taslim and Spring [9] were one of the earliest to show that 
profiles which were rounded, closer to what is found in gas turbines, had significant differences in bulk HTC in the inter rib region. Most recently Taslim and Ren [10] have shown that particulate build up on the upstream or downstream side of ribs may reduce heat transfer by more than $25 \%$ on these surfaces. Rallabandi et al. [11] experimentally investigated the difference caused by rounded rib profiles by comparing results to the sharp edged correlation of Han et al. [12]. This demonstrated a significant change in the friction factor and Nusselt number (respective values from the Rallabandi correlation are up to $19 \%$ and $29 \%$ greater, at the conditions of the current research) and provided empirical correlations. A direct recommendation from the authors was for further work to obtain locally resolved HTC. Jackson et al. [13] presented a comparison of numerical and experimental studies on a highly representative model of a multi-pass internal cooling passage. Although this was a highly complex study, only qualitative judgements can be made due to the results being normalised using an unknown method. Additionally, there is a lack of experimental resolution and measurements were only made on ribbed surfaces. The numerical simulations under-predicted the experimental HTC values on the ribbed wall by up to $20 \%$ for the average values, and up to $25 \%$ for peak values.

The rotation of the passage has a significant impact upon heat transfer through buoyancy and Coriolis forces [14]. Correlations exist to account for the shift in heat transfer for ribbed walls, based on experiments taking bulk heat transfer measurements. Due to the complex nature of rotating experiments, it is very difficult to obtain spatially resolved values for heat transfer. By conducting high spatial resolution experiments under stationary conditions and low resolution rotational experiments, CFD studies can be validated and further numerical studies undertaken to analyse the effect of rotation. There are few rigs that can simultaneously match buoyancy and Coriolis effects.

This paper presents results from stationary experiments of a generic engine representative internal cooling passage, over a range of Reynolds numbers $(18,000-105,000)$ for three aspect ratios (1:2, 1:3 and 1:4), extending the work previously published in the European Turbomachinery Conference proceedings [15]. The geometry used is typical of many low aspect ratio channels, and was chosen to incorporate many features which are challenging for numerical modellers - rounded 
ribs, partial ribs and low aspect ratio. Transient liquid crystal techniques developed by Ireland and Jones [16] and Wang [17] have been implemented to collect HTC over the full surface of the passage and provide bulk HTC on the ribs. Corresponding measurements of pressure drop in the passage were also recorded. Investigations have been conducted into how results differ from those collected in previous studies on more idealised geometry.

\section{Experimental setup}

\section{A. Experimental facility}

A summary of the experimental setup is provided below. Figure 1 presents a schematic of the stationary internal cooling rig, which includes a single pass of a rib turbulated passage. The rig is operated in a suction mode with the outlet plenum connected to a vacuum line, which contains a gate valve in order to set the mass flow rate through the system. A flow straightener and baffle plate are located before and after the test section respectively was shown to promote flow uniformity at the passage entrance eliminating any effect of the exhaust geometry. A heater mesh is situated $400 \mathrm{~mm}$ upstream of the intake to the test section to provide a rapid change in temperature used in the transient liquid crystal technique. Five K-type unshielded gas thermocouples, $0.25 \mathrm{~mm}$ bead diameter, measurements along the centreline, and five static pressure measurements (using multiple pressure transducers, Sensortechnics HCX and BTE ranges) are recorded over the length of the test section, on the trailing edge surface $10 \mathrm{~mm}$ from the centreline. The pressure gradient used to calculate the friction was measured over the range $5<\mathrm{x} / \mathrm{D}_{h}<15$. This compares to $4<$ $\mathrm{x} / \mathrm{D}_{h}<14$ in the studies of Rallabandi et al. [11]. Data was logged at $100 \mathrm{~Hz}$ using a National Instruments data acquisition system (SCXI-1000 chassis containing a SCXI-1102 card) driven by Labview software.

Mirrors are placed above and below the test section at an angle of $45^{\circ}$ to allow the main camera to capture three of the surfaces during a single test. A second camera views a short section of the downstream ribbed wall to capture high spatial resolution data. An LED is present in both cameras' fields of view and is activated when power is supplied to the heater mesh. This provides synchronisation between the video and logged temperature data. The surface is lit by four "warm 


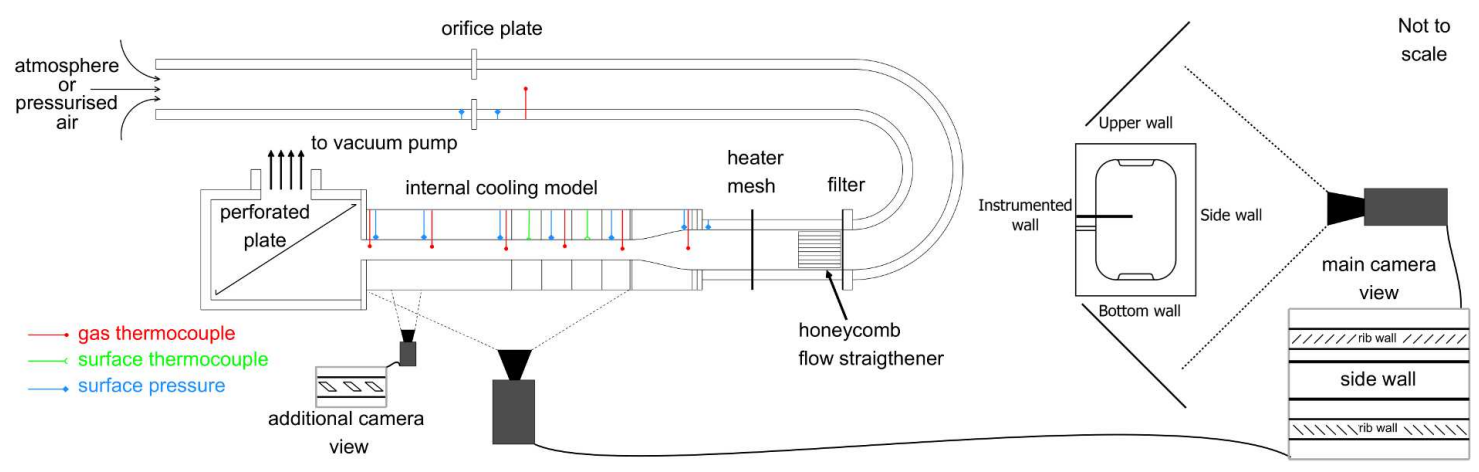

Figure 1. Schematic of experimental setup of flow path, instrumentation and camera view.

white' (3000 K) LED strip lights directed at the test section to provide the best illumination with minimal reflections.

The test section is constructed from cast Perspex sheet (thermal product $569 \pm 29 \frac{W}{m^{2} s^{0.5} K^{1}}$ [18]), which is a good thermal insulator and provides optical access. The internal surface of the test section is coated with a mixture of a binder and three narrow band liquid crystals $\left(1{ }^{\circ} \mathrm{C}\right.$ activation, nominally 25,30 , and $35^{\circ} \mathrm{C}$ for the $1: 2$ and $1: 3$ aspect ratio passages, and 30,35 and $40^{\circ} \mathrm{C}$ for the 1:4). A black ink backing is applied to provide better contrast.

The material thickness would allow the assumption of a 1-D semi-infinite wall to remain valid during a $75 \mathrm{~s}$ test duration for the case of uniform HTC over the surface [19]. In the current study, strong gradients in HTC are expected. Ling et al. [20] and others have shown that lateral conduction (with $x$ and $y$ being non-wall normal directions) may be considered insignificant when:

$$
\frac{d^{2} q}{d x^{2}}<<\frac{q}{2 \alpha t} \text { and } \frac{d^{2} q}{d y^{2}}<<\frac{q}{2 \alpha t}
$$

The high curvature and extremely high HTC gradients expected on the ribs meant that the 1-D conduction equation would clearly be invalid and an alternative approach required. On the plane surface surrounding the ribs, by limiting the test time, the criteria above could be largely satisfied in spite of large changes in HTC. A hybrid technique allows bulk values of HTC to be calculated over the ribs [17]. To use this technique several of the Perspex ribs were replaced with brass inserts. This technique uses a lumped heat capacity model with temperature measured at the Perspex interface since the inserts have a low Biot number $(<0.025)$. The brass inserts were 
backed with the same liquid crystal mixture used on the passage walls to measure temperature and affixed to the Perspex with the binder [17].

During a test, the model is initially isothermal with to the surroundings. Air from the atmosphere is then passed, unheated, through the rig and the mass flow rate is adjusted to obtain the desired Reynolds number.

In the case of the 1:4 aspect ratio passage, the rig was upgraded to use pressurised air instead of an atmospheric inlet. This was done to minimise leaks in the internal cooling passage component of the experiment by maintaining close to atmospheric pressure.

As the pressurised air supplied is typically below ambient temperature, a pre-heater heater mesh was installed in line with the original meshes to maintain isothermal conditions prior to the start of the test. Typically, air passes through the test section for 10 minutes before performing the experiment. Without pre-heating this would cause significant error in the measured HTC.

The test is initiated when power is supplied to the heater mesh. Calibration of all liquid crystals was performed in-situ: the liquid crystal colour play adjacent to a surface thermocouple is recorded as the surface temperature is increased over a fine series of steady state temperatures covering the full colour play range of the liquid crystals. In-situ calibration removes distortion effects caused by lighting or the local white balance of the cameras. Separate in-situ calibrations are required for the Perspex surfaces and hybrid ribs.

\section{B. Passage Geometry}

The internal cooling passage test section consists of a $432 \mathrm{~mm}$ long rectangular duct with radiused corners and rib turbulators on two opposing walls (denoted as suction and pressure surface with reference to their nominal external surfaces). The remaining walls (leading and trailing edge) are smooth as seen in Figures 2 and 3. Ribs in the passage are: at an angle $(\alpha)$ of $45^{\circ}$ to the streamwise direction; a pitch to height spacing $(P / \mathrm{e})$ of 10 ; they are filleted along all edges (radius of filleting is e/2). Importantly the ribs are centred in the passage and span half the width of the passage; they are staggered by half a pitch between the suction and pressure surface. Three aspect ratios (width:height) of 1:2, 1:3 and 1:4 were investigated, with rib blockage (e/D $\left.D_{h}\right)$ of $6.9 \%, 6.2 \%$ and 
$5.8 \%$ and hydraulic diameter of $26.1,29.0$ and $30.8 \mathrm{~mm}$ respectively. The passage width (W) is $18.66 \mathrm{~mm}$. The rig can be reconfigured to allow HTC data to be collected for the fourth wall.

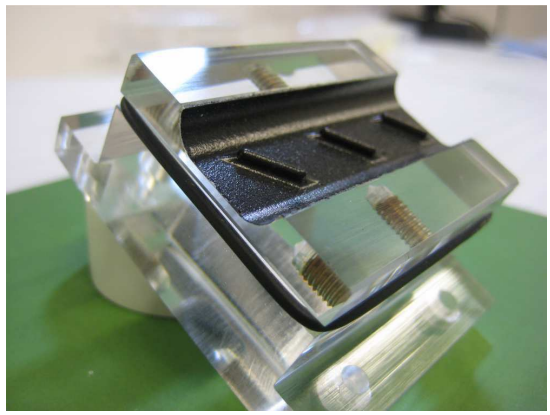

a) Section view of internal cooling passage b) Photograph of ribbed wall part

Figure 2. Schematic and image of rib turbulators in experimental passage.

Surface roughness of the sprayed liquid crystal surface was measured using a Talysurf as Ra $\approx 20 \mu \mathrm{m}$. In this experiment the passage is $4-5$ times engine scale and thus the equivalent roughness height in the engine is $45 \approx 20 \mu \mathrm{m}$, which is engine representative. The roughness is likely to change the HTC level most in the quiescent regions of the flow on the trailing edge wall, but not to the same extent in the highly turbulated regions near the ribbed surface.

\section{HTC data analysis}

Post-processing involves transforming the recorded experimental data of gas temperatures and video into a heat transfer coefficient contour map of the unwrapped inner surface of the internal cooling passage. The recorded video is cropped to only the internal cooling passage surfaces, and a third order power correction for barrel lens effect is applied.

The transient liquid crystal technique provides a nearest match for the HTC value at each pixel location. By modelling the gas temperature as a series of ramps [16] (corrected equation below), surface temperature can be calculated for a given HTC value using the semi-infinite 1D conduction equation (Equation 2). A theoretical green intensity history can then be produced using calibration data. By generating a series of theoretical green intensity profiles at each pixel over a range of HTC values and the recorded driving gas temperature, a nearest value of HTC can then be evaluated by finding the value of HTC which produces the minimum RSS difference between the recorded and theoretical intensity profiles. In this work the centreline gas temperature is used to calculate the 
HTC while the gas temperature is linearly interpolated between the thermocouples for each pixel.

$$
\begin{gathered}
T_{s}=T_{0}+\sum_{i=1}^{n} \mathrm{~m}_{i} t\left(1-\frac{2}{\beta_{i} \sqrt{\pi}}+\frac{1-\exp \left(\beta_{i}^{2}\right) \operatorname{erfc}\left(\beta_{i}\right)}{\beta_{i}^{2}}\right), \\
\beta_{i}=\frac{h\left(t-t_{i}\right)^{\frac{1}{2}}}{\sqrt{\rho c_{p} k}}, \quad \mathrm{~m}_{i}=\frac{\left(\Delta T_{g a s, \infty}\right)_{i}}{\Delta t}
\end{gathered}
$$

The hybrid rib method operates in the same manner using adjusted versions of the appropriate equations [17] for pixels located on the ribs. Equations 4 and 3 are used to calculate the heat transfer coefficient on the rib, using the definition of variables given in Equation 5. The reported HTC is then based on the plan area of the rib within the passage. This allows immediate comparison of different rib design. After the HTC is calculated for each pixel on a given rib, any outliers are rejected before the median is taken as the rib's HTC level.

$$
\begin{gathered}
T_{s}=T_{0}+\sum_{i=1}^{n}\left[U\left(t-t_{i}\right) \Delta\left(T_{\text {gas }, \infty}\right)_{i}\right] \\
U\left(t-t_{i}\right)=1-\frac{h}{\beta_{\mathrm{rib}}}\left[\frac{\exp \left(a^{2}\left(t-t_{i}\right)\right) \operatorname{erfc}\left(a \sqrt{t-t_{i}}\right)}{a(b-a)}-\right. \\
\left.\frac{\exp \left(b^{2}\left(t-t_{i}\right)\right) \operatorname{erfc}\left(b \sqrt{t-t_{i}}\right)}{b(b-a)}\right] \\
\beta_{\text {rib }}=\rho_{\text {rib }} c_{p_{\mathrm{rib}}} z_{\mathrm{rib}}\left(1-\frac{h l_{\mathrm{rib}}}{2 k_{\mathrm{rib}}}\right) \\
A=\frac{\sqrt{\rho c_{p} k}}{2 \beta_{\mathrm{rib}}}, \quad B=\sqrt{A^{2}-\frac{h}{\beta_{\mathrm{rib}}}} \\
a=A-B, \quad b=A+B
\end{gathered}
$$




\section{A. Recombination and transformation to spatial dimensions}

The data from each surface is transformed using a linear interpolation to account for non-linearity in radial geometry and rotation, then combined to form a single map (Figure 3). Where there is an overlap between images, the data is cropped to the midpoint of the passage fillet for recombination. This minimises the area scaling applied to individual pixels. Each wall is appropriately rotated to reflect the layout of the experimental passage.

To account for radial conduction in the concave corners, the curvature correction method of Buttsworth and Jones [21] has been applied. This allows for a simple procedure in correcting for the radial conduction with reasonable accuracy after finding values of $\theta_{f p}$ and $h_{f p}$ at each pixel location using Equation 6. If a surface has a known HTC value $\left(h_{\text {true }}\right)$ then the approximate nondimensional surface temperature response in the presence of radial conduction $\left(\theta_{\text {true }}\right)$ is provided by Equation 6, where $\mathrm{c}=-1$ for concave surfaces and +1 for convex.
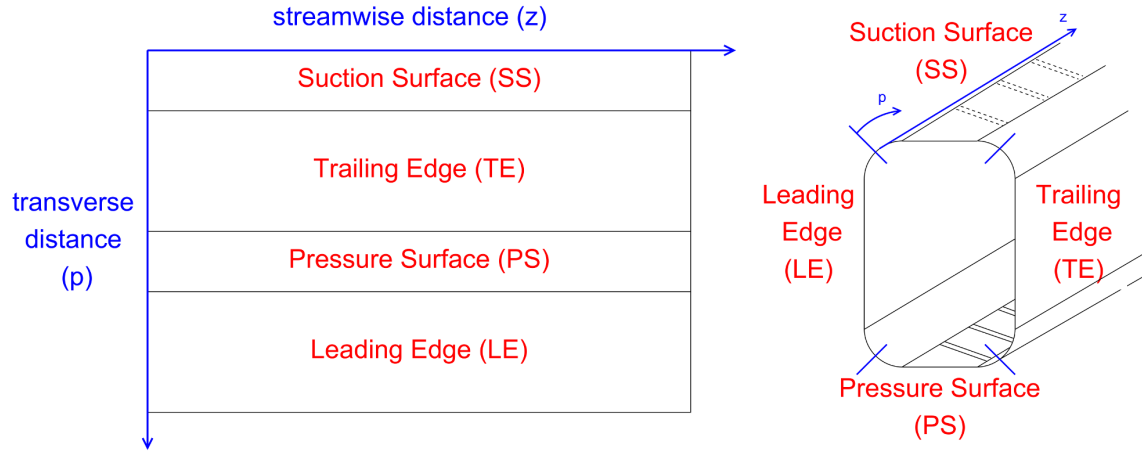

Figure 3. Schematic for recombination of individual HTC maps into a unitary map

$$
\theta_{\text {true }}=\theta_{f p}\left(1+\frac{c k}{2 R h_{f p}}\right), \quad h_{f p}=h_{\text {true }}-\frac{c k}{2 R}
$$

\section{B. Uncertainty Analysis}

The perturbation method of Kline and McClintock [22] has been applied to calculate the uncertainty in experimental measurements, assuming all experimental uncertainties are independent. The following experimental uncertainties were applied based on both the measurement uncertainty and experimental fluctuation/non-uniformity: time $0.033 \mathrm{~s}(0.04 \mathrm{~s}$ for the secondary camera); liq- 
uid crystal calibration $0.5 \%$, initial temperature $0.5 \%$, gas temperature $0.5 \%$ all as temperature in ${ }^{\circ} \mathrm{C}$; Perspex thermal product $5.1 \%$. For the hybrid ribs: density $0.5 \%$; specific heat capacity $5 \%$; thermal conductivity 5\%. Mass flow rate measurements are calculated to have an uncertainty of less than $1.3 \%$ and friction factor of typically less than $2 \%$. Using the uncertainty of each measurement, a maximum uncertainty has been assessed at each pixel location and presented in the form of contour maps (Figure 4).

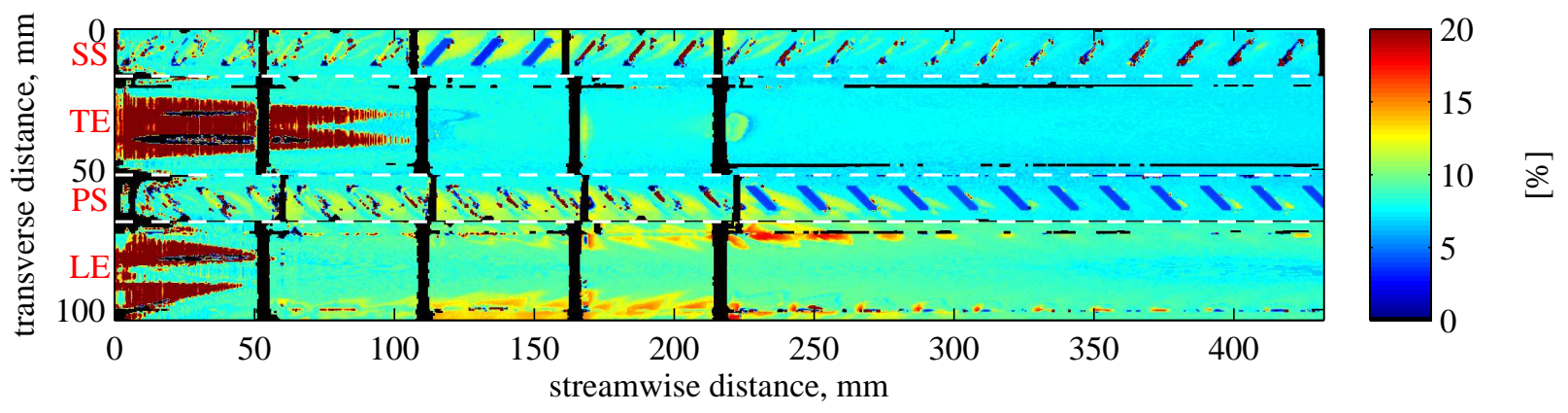

Figure 4. Combined total uncertainty in HTC map for a Reynolds number of 60596, AR 1:2.

The HTC uncertainty depending on the geometric and flow features in the region typically ranges from $6-18 \%$ for the Perspex test section and is $6 \%$ for the hybrid ribs. The uncertainty for the higher resolution images is up to $10 \%$ lower than the main camera, showing that resolution has a significant impact on the uncertainty. This is due to strong gradients in HTC in the inter-rib region resulting in choice of HTC level by RSS minimization procedure. Repeated experiments for both aspect ratios showed agreement within $10 \%$, which is lower than the maximum calculated value of $18 \%$, though similar to the average value of under $10 \%$. Applying the empirical correlations of Han et al. [12], the mass flow rate uncertainty relates to spatially averaged uncertainty in HTC of $\leq 2 \%$.

\section{Correlations and data normalisation}

Experimental results are compared to correlations from the literature, however, applicability is dependent on experimental passage geometry. Unfortunately there are no fully comparable cases. For comparison of aspect ratio influences, the correlation of Han et al. [12] is used for a sharp cornered passage with full width sharp-edged ribs. To allow the additional effect of rib rounding 
to be considered, further comparison is made to the correlation of Rallabandi et al. [11] this uses a square passage geometry identical to that of Han et al. but with ribs with fillet radii of half the rib height (e/2). These latter results are anomalous with the current experiments as they use ribs which span the entire ribbed wall width compared to the half the width in the current testing (see Figure 2). Both correlations used for comparison are for the ribbed surfaces only, and the second does not account for differences in aspect ratio. Thus, only the pressure / suction surface $\mathrm{Nu}$ distributions are compared to the correlations. Nusselt number and friction factor data are normalised by the Dittus-Boelter (Equation 7) and Blasius (Equation 8) relations for turbulent, fully-developed smooth pipe flow. Experimental averages are taken over the downstream half (216 - $432 \mathrm{~mm}$ ) of the passage, where the flow is more developed and bulk HTC values have been calculated for the ribs.

$$
\begin{aligned}
\mathrm{Nu}_{0} & =0.023 \operatorname{Re}_{D_{h}}^{0.8} \operatorname{Pr}^{0.4} \\
f_{0} & =0.079 \operatorname{Re}_{D_{h}}^{-0.25}
\end{aligned}
$$

Comparison of results to empirical correlations, although useful, is acknowledged as having limitations. First, on the smooth walls, the present experimental data may not be fully developed over the region where average data is taken. Additionally, the experimental data on which the Rallabandi et al. [11] correlation is formulated has streamwise variations in normalised Nusselt numbers of up to $\sim 25 \%$ over the region where the flow is assumed to be fully developed. This is perhaps unsurprising when the local data of the current study are interrogated, as flow development is seen to take longer than had previously been assumed. Secondly, the present experimental HTC values are based on interpolated centreline temperatures and not mixed bulk temperatures used in the correlations, which can lead to significant discrepancies as shown in the associated numerical simulations [23]. In contrast, the Rallabandi et al. [11] HTC data is calculated from a single point measurement of the temperature. Finally, the present geometry is slightly outside the range tested when creating both correlations. However, this effect may be minimal due to a large spread of e/ $D_{h}$ values (9.4-18.8\%) used in the correlations development and with knowledge that the Han et 
$a l$. [12] correlation has been verified by experimental data for lower e $/ D_{h}$ configurations.

\section{Results}

Heat transfer coefficient distributions have been measured over the full internal surface of three aspect ratio configurations $(1: 2,1: 3,1: 4)$ at five Reynolds numbers $(18,000-105,000)$. Streamwise static pressure measurements were taken over a finer range of Reynolds numbers to evaluate the frictional losses for all aspect ratios. The heat transfer results are presented as Nusselt number, based on the hydraulic diameter of an unturbulated passage, and the average air temperature over the test duration at each pixel location. Prandtl number was taken to be 0.71 . Where there are corrupt data (such as at the joints in the model) these are set as null data for averaging purposes, but displayed as zero values in contour plots. It should be noted that for the AR 1:4 model, most joints along the passage were eliminated. Where there are Perspex ribs in the model, accurate $\mathrm{Nu}$ values cannot be calculated without a 3-D conduction correction. Thus the values at these locations are also nulled.

Figure 5 presents examples of the spatially resolved Nusselt number data on the internal surface of each passage. These maps demonstrate the typical heat transfer patterns observed for all aspect ratios and all Reynolds numbers. The Nusselt number is low on the all walls of the passage at its entrance as it is fed from a region of developed flow upstream. On both the pressure and suction side ribbed-walls the $\mathrm{Nu}$ levels quickly rise and are always generally higher than for the smooth walls, however, it is notable that near steady $\mathrm{Nu}$ levels are not achieved over the first half of the passage. As with full width ribs, high heat transfer is observed in the reattachment regions between each rib. For these partial width ribs there are also areas of very $\mathrm{Nu}$ enhancement aligned with the ribs, at their downstream edge. At high Reynolds numbers (not presented here for brevity), the level of enhancement is equivalent to that found on the rib itself, and these extend approximately half-way around the filleted surface. Considering the smooth walls, the Nusselt number is higher on the leading edge side of the cooling passage than the trailing edge side. Here, the highly turbulated secondary flow in the inter-rib regions of the ribbed walls are able to run onto the leading-edge because of the large corner fillets. These corner fillets eliminate some flow impingement features 
previously observed in rectangular passage corners, but increase heat transfer on sidewalls. A region of lower Nusselt number runs along the centre of the leading edge wall, and this is lower than the average Nusselt number on the opposing trailing-edge wall. The region is associated the detachment of the secondary flow, which forms a characteristic pair of passage vortices when ribs of equal angle are employed on both ribbed surfaces. In contrast, variation in Nusselt number across the trailing edge is low, with values slightly higher near the centre of the wall.

Figure 6 presents the experimental $\mathrm{Nu}$ distributions averaged around the passage perimeter. The averaged results are sub-divided into different regions as shown in the figure legend to highlight trends and contributions to Nusselt number down the passage. The data are normalised by the Dittus-Boelter correlation for fully developed turbulent flow $\left(N u=0.023 \operatorname{Re}^{0.8} \operatorname{Pr}^{0.4}\right)$, allowing a measure of heat transfer enhancement compared to a circular smooth-walled passage of equal hydraulic diameter to be observed. The occasional discontinuities (spikes and dips) seen in the data correspond to the location of joints in the test rig (which restrict views cause slight misalignment and boundary layer disruption). Values on the ribs are only reported where hybrid ribs were present. For all aspect ratios, the averaged Nusselt number enhancement is locally 2-3 times larger than in the inter-rib areas. This is partly due to the data being presented based on projected area: if based on surface area, a 33\% decrease in average Nusselt number would be expected on the ribs. Nusselt number does not completely plateau (i.e. plateau with streamwise distance) for any of the aspect ratios or Reynolds numbers investigated.

Comparing the aspect ratios, the pattern of Nusselt number is generally very similar in terms of the overall features. However, secondary flow is seen to extend further across the leading edge as aspect ratio increases (i.e. moving from 1:4 to 1:2). A noted feature in the distributions is a higher value in average Nusselt number, located close to $220 \mathrm{~mm}$ and again near $400 \mathrm{~mm}$ for the 1:2 aspect ratio, and further downstream at $\sim 275 \mathrm{~mm}$ when moving to the 1:3 aspect ratio. In the 1:4 aspect ratio passage, this highest value occurs at or beyond the passage exit. The peaks in Nusselt number are associated with periodically changing secondary flow characteristics of large streamwise length scale. Evidence from flow field studies, presented in Forsyth et al. [24], show that the rotational vortices induced by the presence of the ribs grow in strength within the 


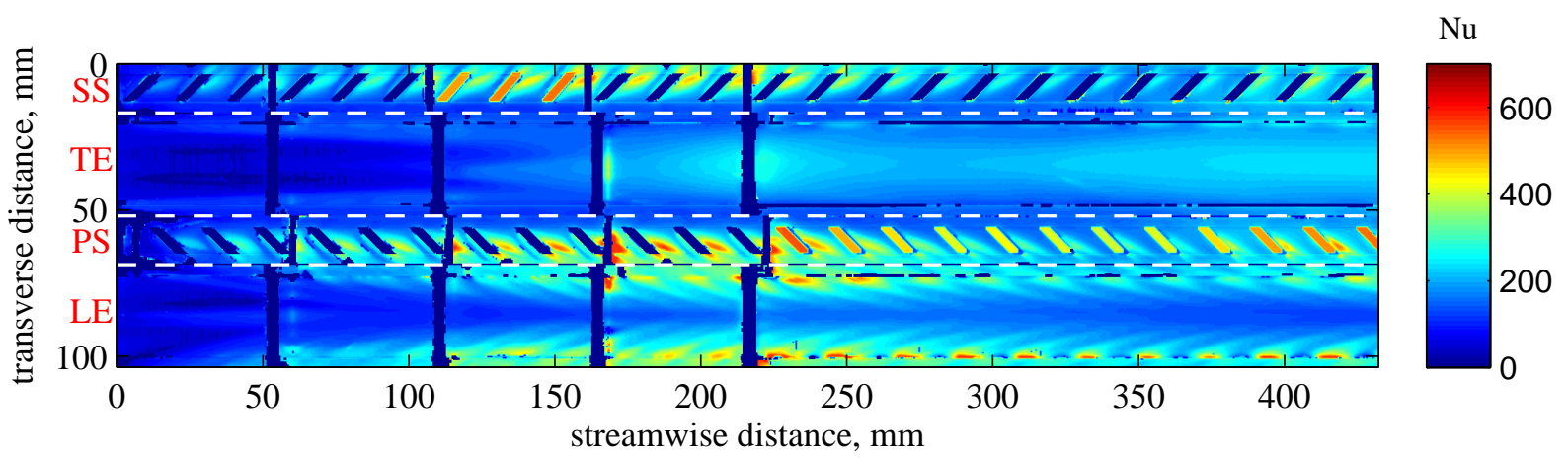

a) Nusselt number maps for a Reynolds number $=60,596$ at an aspect ratio of 1:2.

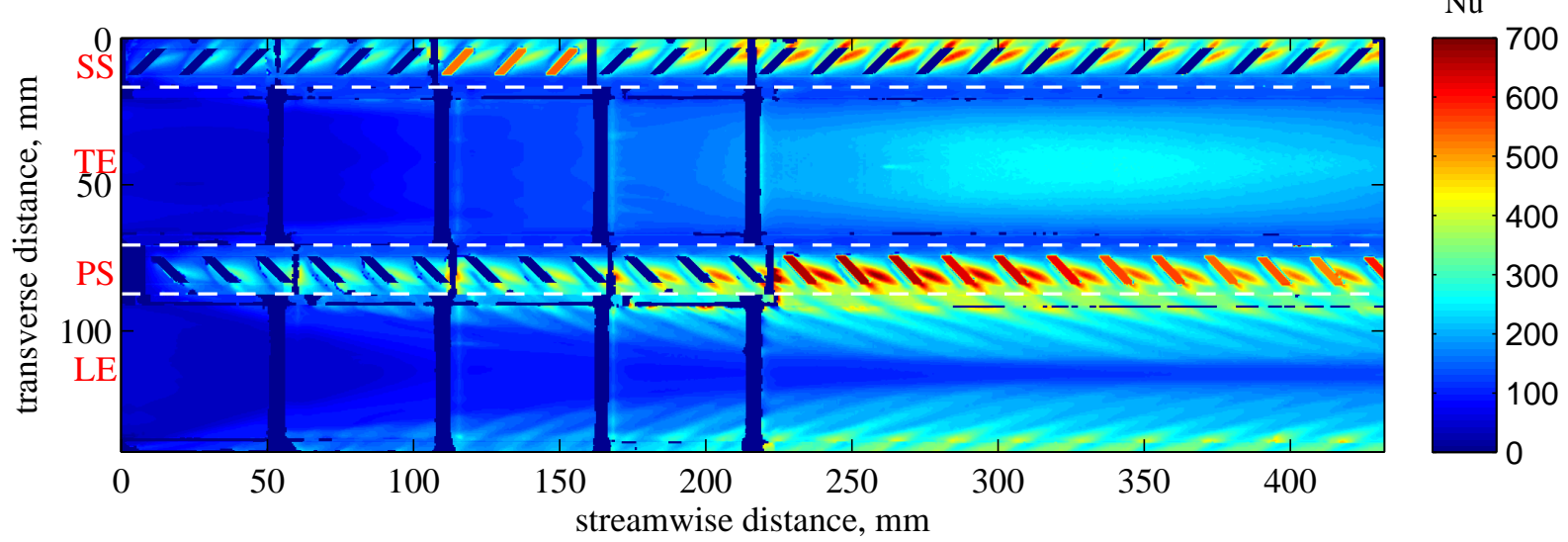

b) Nusselt number maps for a Reynolds number $=59,409$ at an aspect ratio of 1:3.

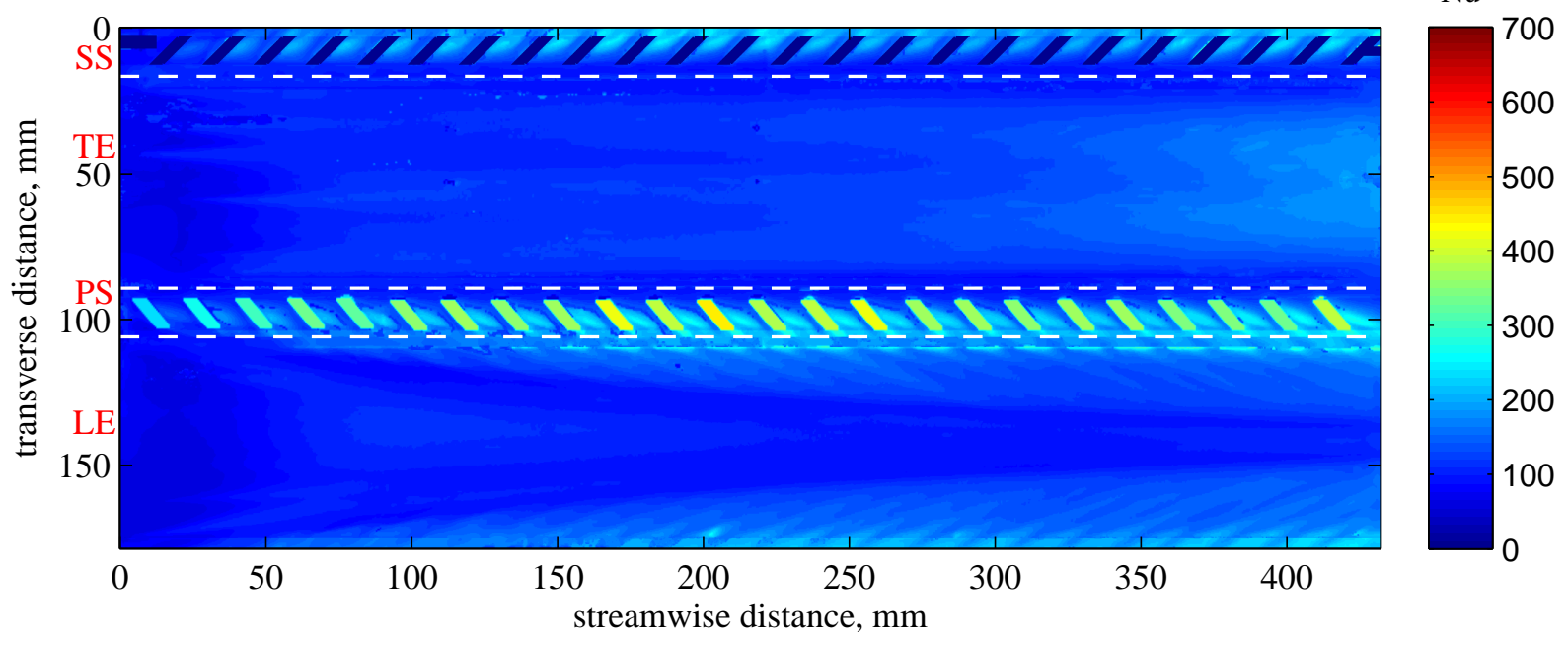

c) Nusselt number maps for a Reynolds number $=57,829$ at an aspect ratio of 1:4.

Figure 5. Nusselt number distributions for all aspect ratios at a Reynolds number at $\sim 60,000$.

passage until they strongly impinge onto the mid-height region of the trailing edge wall. Here, occupying the entire passage cross-section they are strongly sheared by the axial flow causing them 


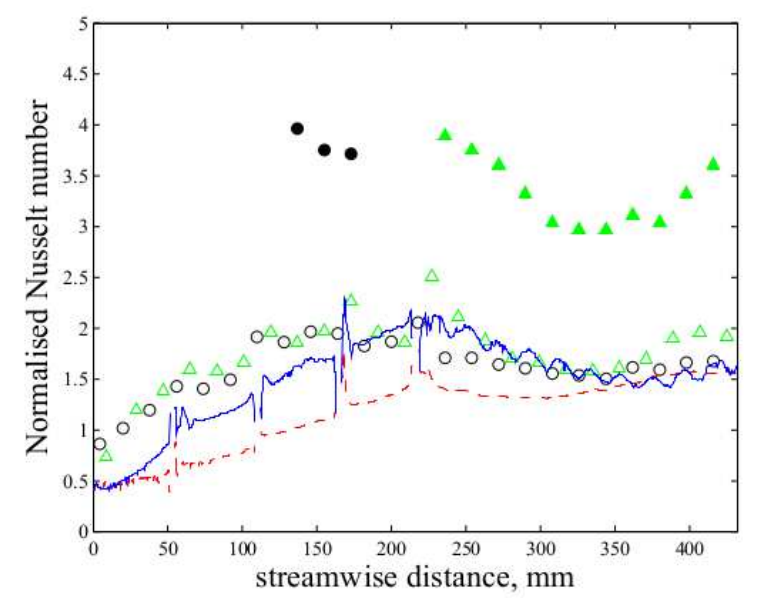

a) $\mathrm{AR}=1: 2, \operatorname{Re}=60,596$

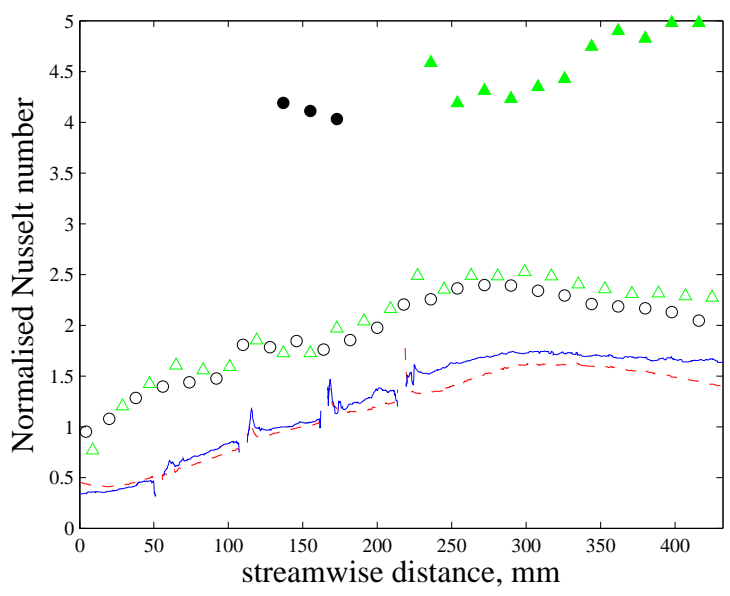

b) $\mathrm{AR}=1: 3, \operatorname{Re}=\mathbf{5 9 , 4 0 9}$

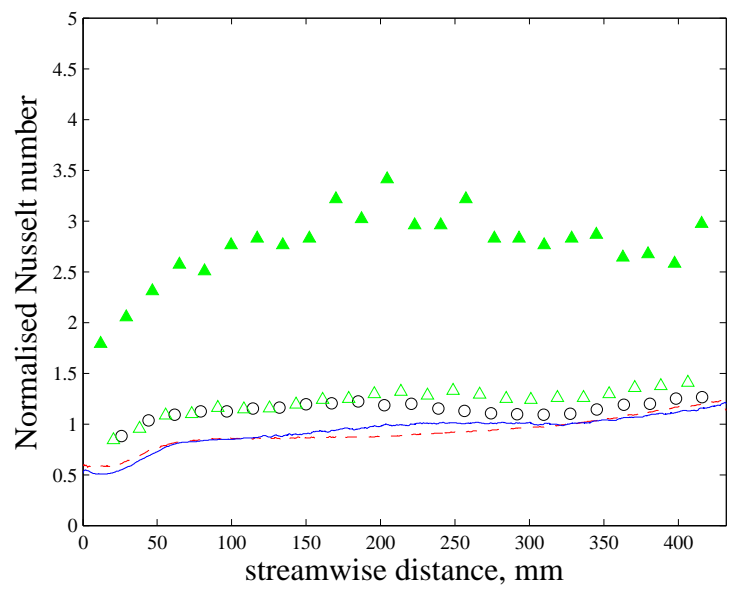

- SS inter-rib average

- SS rib average

- TE average

$\triangle$ PS inter-rib average

$\triangle \quad$ PS rib average

c) $\mathrm{AR}=1: 4, \operatorname{Re}=57,829$

Figure 6. Average normalised Nusselt number streamwise distributions for both aspect ratios at a Reynolds number of 60,000. Note: the AR 1:4 used continuous side walls eliminating areas of undefined HTC. The averaging method is included with Figure 8

to breakdown. Once alternative flow paths for the mainstream flow are available the secondary flow strengthens again. The double peak on the trailing edge of the 1:2 aspect ratio passage indicates that this process can repeatedly occur. This behaviour has been confirmed by CFD simulations with an extended passage [23], with a wave like pattern in the Nusselt number observed. If the streamwise axes of this plots are scaled by passage height, then the peaks on the trailing edge wall are seen to align and occurs at approximately six times the passage height for all three aspect ratios. For the AR 1:4 passage, this was only observed numerically when the passage was artificially extended.

The smooth walls in the 1:2 aspect ratio passage show significant Nusselt number enhancement, after the first few rib repeats. This is unsurprising, as most of the surface is washed by 
ribbed wall secondary flow. However, as the aspect ratio reduces, so does the performance of the smooth walls, with the leading and trailing edge values becoming similar, and in the case of the 1:4 aspect ratio passage slowly increasing towards unity. (Note that the initial value below unity is to be expected for results based on a developed centreline temperature profile, where the centreline to wall temperature difference may be significantly higher than the mixed bulk temperature difference).

While it might not be surprising that the smooth wall values are lower for the 1:4 passage, on the ribbed walls, the data clearly shows a much lower Nusselt number distribution than for the other two geometries. This may be caused by the use of an interpolated centreline gas temperature to calculate the HTC (7), and thus Nu distribution. In the low aspect ratio geometry, along the, centreline there is eveidence of a core of high heat transfer potential air, which travels down the passage undergoing little mixing with the rotating vortices established near the ribbed walls - and thus its temperature is maintained close to the inlet temperature. This behaviour is indicated for the 1:4 aspect ratio by centreline gas temperature distributions which show little variation with streamwise distance along the passage until a thermocouple situated $428 \mathrm{~mm}$ from the inlet. This is shown in Figure 7, where the centreline thermocouples 12 seconds from the start of the test are displayed for typical tests in the three passages. This is not the case for the other aspect ratios, and highlights known difficulties in basing HTC calculations on a pointwise temperature measurements, rather than a mixed bulk temperature derived from an energy balance. In both cases it should be noted that provided the temperature is known the local heat flux can be reconstructed, but as there is a temperature distribution across the passage, the heat flux will not scale completely unless the full adiabatic wall temperature distribution is known. The variation in centreline temperature, observed in the experiments, is supported by complimentary CFD conducted at nominally the same conditions, where highly non-uniform streamwise cross-sectional temperature distributions were predicted for the 1:4 aspect ratio passage compared to the 1:2 and 1:3 aspect ratios.

Figure 8 presents the projected area averaged Nusselt number for the downstream half of the passage to compare where the flow is more developed, and empirical correlations for the ribbed wall. The results clearly show the impact of Reynolds number on average Nusselt number, and 


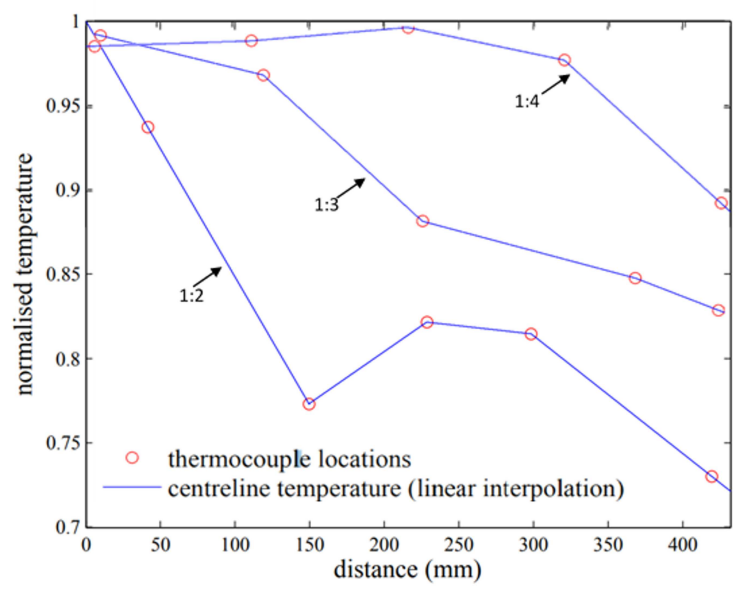

Figure 7. Comparison of interpolated Centreline Temperature in the 1:2, 1:3 and 1:4 Aspect Ratio Passages. Note that the secondary flow progressively affects the temperature along the centreline.

that engine realistic features impact heat transfer magnitude compared to idealised geometry. For the 1:2 aspect ratio configuration, the average Nusselt number is consistently lower than the correlations, while the deviation is seen to increase with Reynolds number. In contrast, the pressure surface average for the 1:3 aspect ratio results continues to increase above the correlation as Reynolds number rises. For the 1:4 aspect ratio geometry at the two lower Reynolds numbers, good agreement is seen between the experimental results and the Rallabandi et al. correlation. This agreement deteriorates with increased Reynolds number, leading to values that are below both correlations at the two highest Reynolds numbers investigated.

For the 1:2 and 1:3 aspect ratio geometries, as Reynolds number increases the leading edge average value is seen to tend towards the ribbed wall average, whilst the trailing edge average falls relative to the total passage average, reflecting stronger secondary flow. This behaviour is not apparent in the 1:4 aspect ratio passage, and the leading and trailing edge walls produce similar average values, which are very similar to the smooth passage correlation. Using average values for the pressure surface Nusselt number, power laws were developed, as presented in Equations 9, 10 and 11 .

$$
\begin{aligned}
& \mathrm{Nu}_{1: 2}=0.392 \mathrm{Re}_{D_{h}}^{0.590} \\
& \mathrm{Nu}_{1: 3}=0.432 \mathrm{Re}_{D_{h}}^{0.603}
\end{aligned}
$$




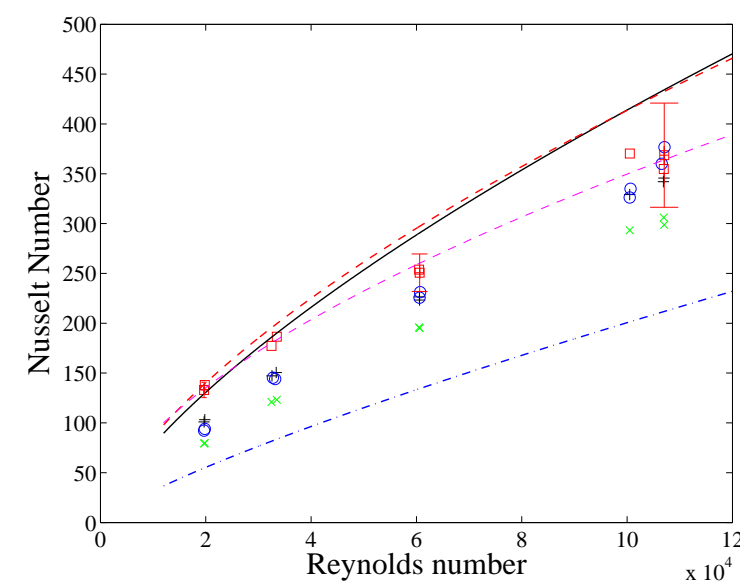

a) $\mathrm{AR}=1: 2$

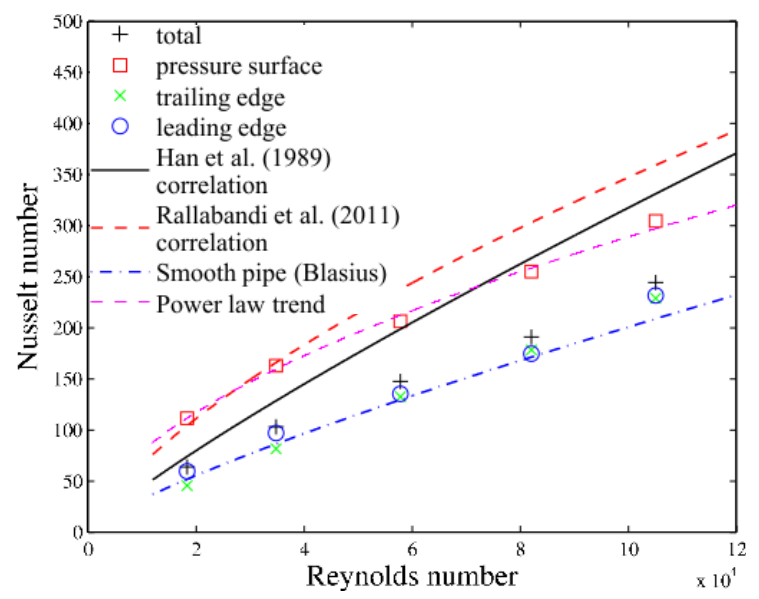

c) $\mathrm{AR}=1: 4$

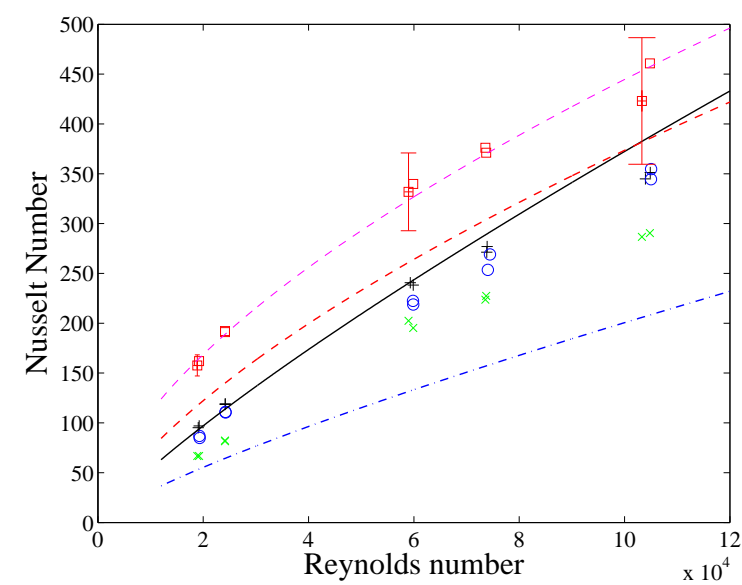

b) $\mathrm{AR}=1: 3$

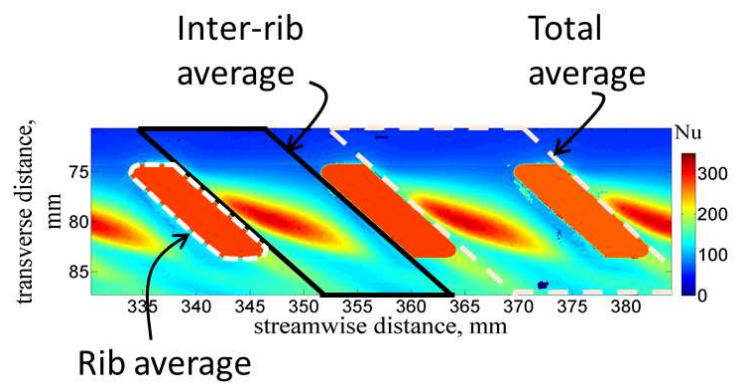

d) Averaging method

Figure 8. Projected area averaged Nusselt number for the downstream half of the passage as a function of Reynolds number compared to correlations for the ribbed wall.Note: Rallabandi et al correlation is for a square passage of equivalent hydraulic diameter.

$$
\mathrm{Nu}_{1: 4}=0.447 \operatorname{Re}_{D_{h}}^{0.562}
$$

High resolution data (Figure 9, rib values are based on projected area) highlights the shift of heat transfer towards the leading edge and is reduced (compared to the rib value) on the trailing edge side of the ribbed wall with increasing Reynolds number. These data are only available for the 1:2 and 1:3 aspect ratio geometries since experimental constraints prevented corresponding data being captured during the same test with the 1:4 aspect ratio. As the vortical flow features strengthen (with Reynolds number), the level of Nusselt number in the reattachment region lessens in comparison to the ribs. In the 1:3 passage, the reattachment region has a comparable Nusselt number to the rib. In contrast, the higher axial velocity in the AR 1:2 passage appears to weaken 
this feature. The high resolution maps agree well with the full surface map (typically within $6 \%$ on the planar sections). The increased resolution reveals greater subtleties of the heat transfer, especially where the secondary flow washes up onto the leading edge wall. Due to the small size and high gradient of some of these features, local discrepancies between the high and low resolution images can be up to $20 \%$, although changes in the averaged values are minimal.

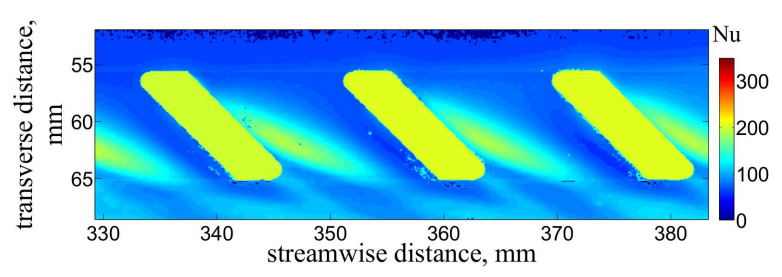

a) $\operatorname{AR} 1: 2, \operatorname{Re}=19,686$

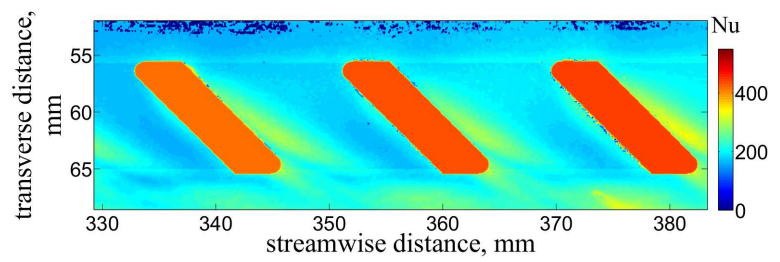

c) $\mathrm{AR} 1: 2, \operatorname{Re}=60,582$

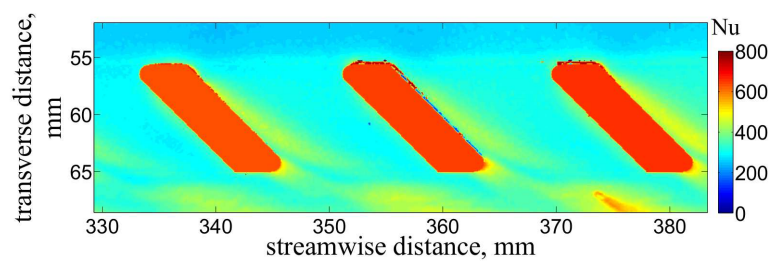

e) $\mathrm{AR} 1: 2, \operatorname{Re}=106,582$

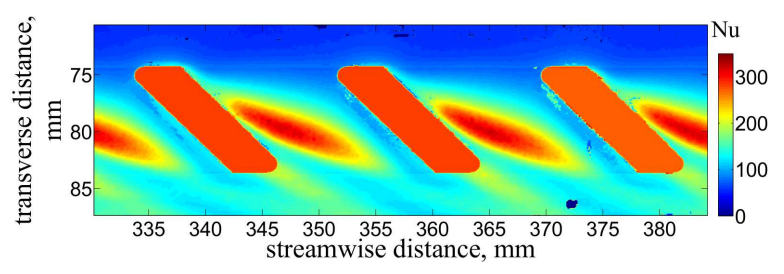

b) $\mathrm{AR} 1: 3, \mathrm{Re}=19,331$

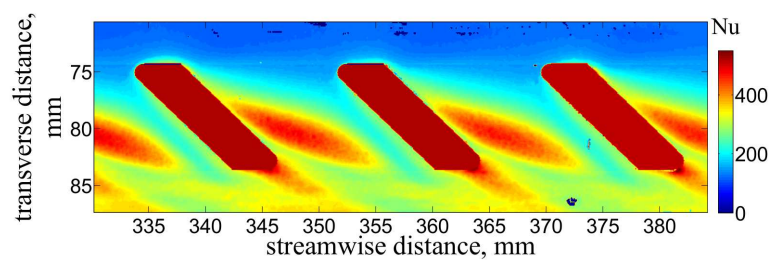

d) AR 1:3, Re = 59,835

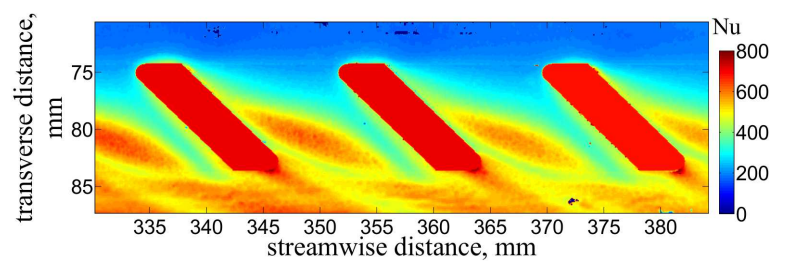

f) $\mathrm{AR} 1: 3, \operatorname{Re}=105,013$

Figure 9. Nusselt number distributions of the pressure side walls between the 1:2, 1:3 aspect ratios.

Caution must be applied when drawing conclusions from the data presented. A fairer comparison of performance could be made by plotting the total heat transferred per unit volume, $\mathrm{Nu} . A_{\text {surface }} / A_{x} . L$, versus the mass flow rate per unit cross-sectional area for the two passages (Figure 10 , data is scaled to $\mathrm{T}_{\text {gas }}=45^{\circ} \mathrm{C}$ ). While the data nearly collapses to a single trend for each surface, the 1:3 passage provides the best performance based on the total passage average and the 1:4 passage again offers the worst performance.

Figure 11 compares the experimental normalised friction factor results with empirical correlations. As previously discussed in this paper, the correlations have been developed for a different geometry and flow development. As expected, the friction factor results are not seen to completely 


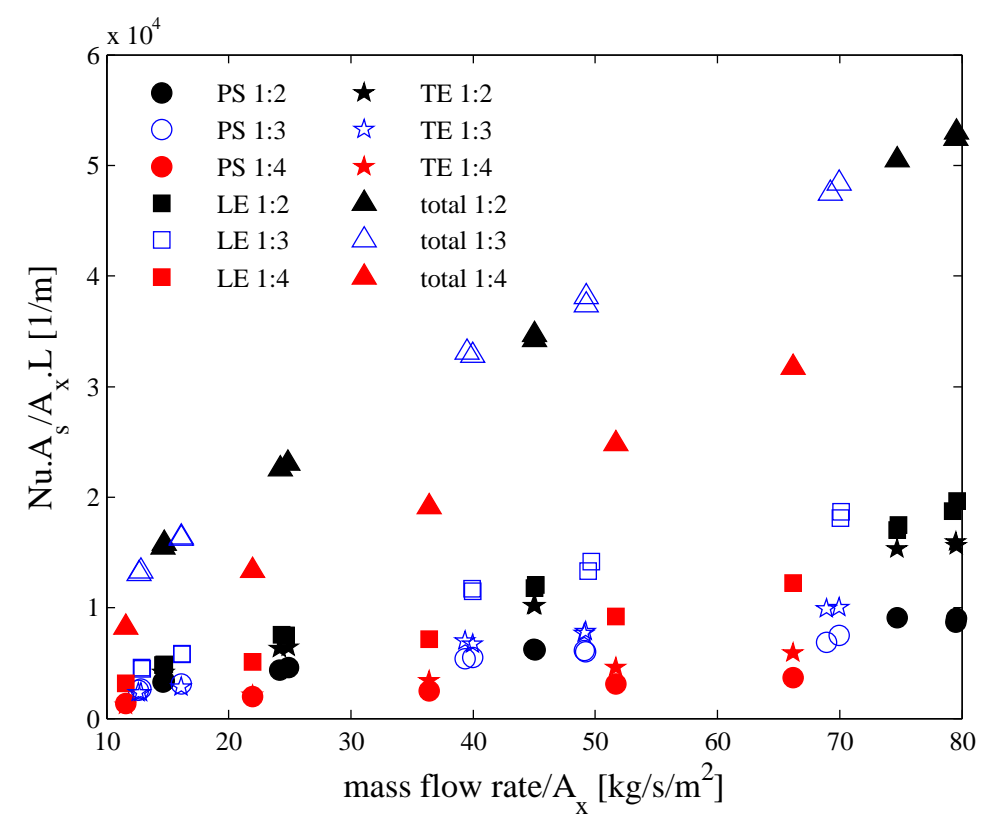

Figure 10. Non-dimensional based measure of average heat transfer potential vs. mass flow rate scaled by cross sectional area occupied.

agree with either of the correlations, although the 1:3 aspect ratio results are the closest, and the 1:4 aspect ratio passage the poorest. It is interesting to note that the friction factor for the 1:3 and 1:4 aspect ratio passages is very similar. It is speculated that this is attributable to the secondary flow interaction. Secondary flows are known to be the major driver of pressure loss in rib turbulence passages(when ribs are inclined to the mainstream flow. Since the rib height remains fixed for all cases, the secondary flow feature may be of comparable strength. It is suggested that for the 1:2 aspect ratio passage these flows interact strongly, however, for the 1:3 and 1:4 aspect ratio passages flow interaction is much weaker. The weak interaction for the 1:3 and 1:4 aspect ratio passages limits the pressure losses incurred, and accounts for the similar pressure loss observed.

Conventionally, when investigating internal cooling passages the performance is assessed by calculating the thermal performance (Equation 12). The results for the current research are presented in Figure 12, along with the corresponding correlations provided by Rallabandi et al.. The Han et al. correlations have been omitted in this figure to maintain readability. The correlation shows poor agreement to the experimental results, although the general profile of the trend with Reynolds number is in agreement for all aspect ratios. As expected, the general trend is a reduced thermal performance with increasing Reynolds number, and all passages provide a performance 


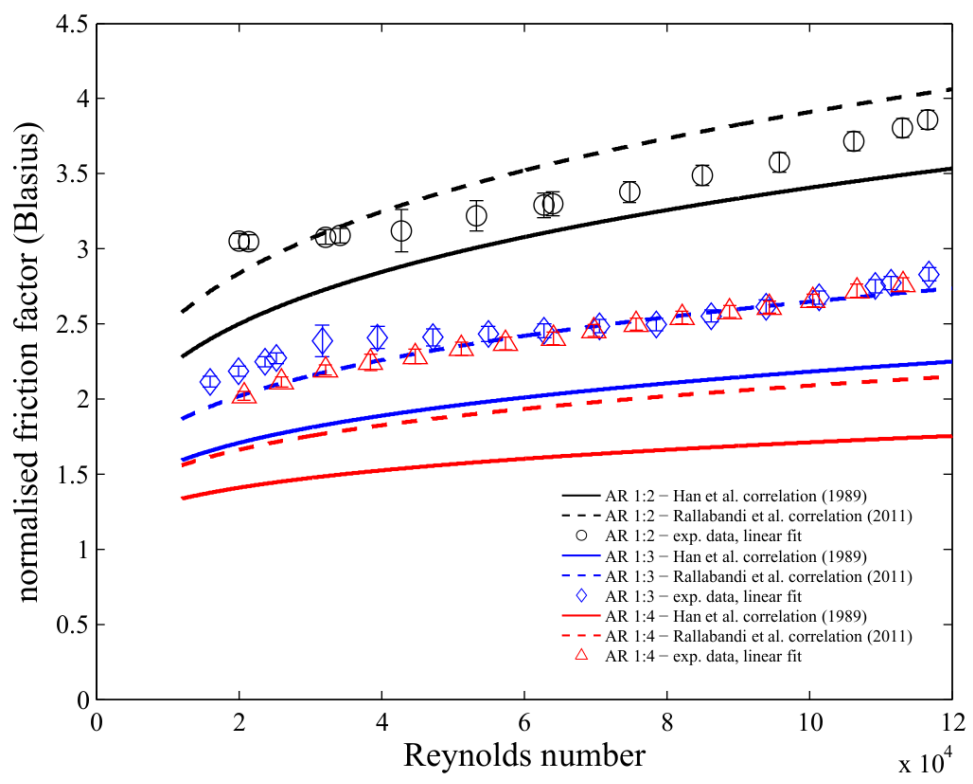

Figure 11. Normalised friction factor as a function of Reynolds number for both aspect ratio configurations.

greater than 1 (i.e. better than a smooth pipe).

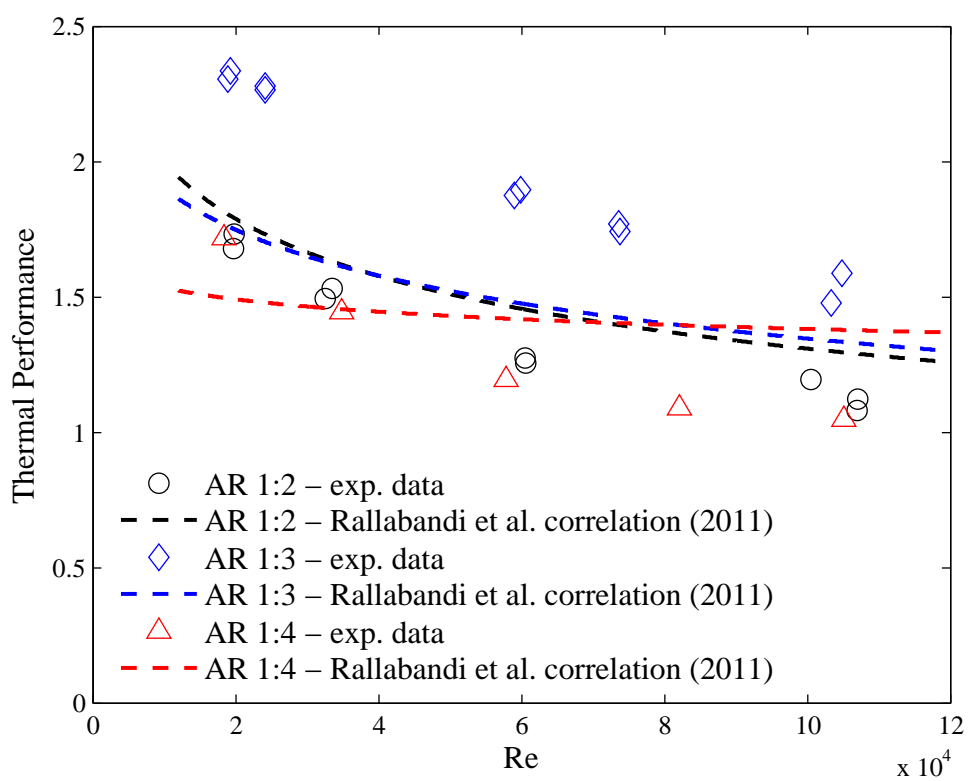

Figure 12. Thermal performance, based on the ribbed wall only (pressure surface)

$$
T P=\frac{\frac{N u_{\mathrm{proj}}}{N u_{\mathrm{o}}}}{\left(\frac{f}{f_{\mathrm{o}}}\right)^{1 / 3}}
$$




\section{Summary and conclusions}

Heat transfer and pressure loss measurements have been made in a stationary engine representative internal cooling passage. Spatially resolved heat transfer data and corresponding uncertainties were obtained over the full surface of the test section. With the use of a hybrid rib technique, bulk values of HTC have been presented on the rib turbulators. The overall profile of heat transfer was similar for all aspect ratios and Reynolds numbers, though local behaviour changed significantly especially around the ribs. With increasing Reynolds number, spatial gradients of Nusselt number were seen to increase with increased heat transfer on the two side walls linked to increased strength of secondary flows.

The 1:4 aspect ratio passage offered the lowest average Nusselt numbers for all surfaces, with the 1:3 passage provided the highest values. The low levels of the 1:4 passage have, in part, been associated with a hot core flow along centreline (where the thermocouples were located) and a low level of mixing. This also driven by the 1:4 passage flow being less developed over the same length. If applied in a real turbine blade, the non=dimensional height of passage to length would be fixed, thus, caution is recommended when performing experiments on low aspect ratio passages.

The structure of heat transfer has been shown to be highly complex, which draws into question the suitably of using average values to asses the performance. Agreement to correlations was generally poor for the more engine realistic geometries investigated in the current research. This indicates that, while of use, great care should be used when applying correlations to passages that differ even slightly from those used to generate them.

The spatially resolved distributions over the full surface provides a greater understanding of the heat transfer structures, allowing validation of CFD studies and diagnosis of areas in which modelling is insufficient. Moreover, the full surface maps are key to recognising the non fully developed Nusselt number structure. With the use of numerical tools, additional drivers of heat transfer, such as rotation and film cooling bleed holes, can be added with knowledge of the accuracy of the stationary passage heat transfer. 


\section{Acknowledgement}

This research received funding from the European Union Seventh Framework Programme (FP7/2007-2013)

under grant agreement no. 233799 (ERICKA). The authors acknowledge the contributions to this

work from Trevor Godfrey, Gerald Walker, Dave Mountain, Duncan Blake, and EDM.

\section{References}

[1] Alfaro-Ayala, J., Gallegos-Muñoz, A., Riesco-Av́illa, J., Flores-Loṕez, M., Campos-Amezcua, A., and Mani-Gonzale, A., "Analysis of the flow in the combustion - transition piece considering the variation in the fuel composition," Journal of Thermal Science and Engineering Applications, Vol. 3, 2011.

[2] Plaut, R. L., Herrera, C., Escriba, D. M., Rios, P. R., and Padilha, A. F., "A Short review on wrought austenitic stainless steels at high temperatures: processing, microstructure, properties and performance," Materials Research, Vol. 10, 12 2007, pp. 453 - 460.

[3] Han, J. C., Dutta, S., and Ekkad, S., Gas Turbine Heat Transfer and Cooling Technology, Taylor and Francis, 2000, ISBN: 15603284.

[4] Han, J. C., "Turbine Blade Cooling Studies at Texas A and M University: 1980-2004," Journal of Thermophysics and Heat Transfer, Vol. 20, 2006, pp. 161-187.

[5] Walker, D. and Zausner, J., "RANS evaluation of internal cooling passage geometries: Ribbed passages and a 180 degree bend," ASME Turbo Expo, Paper GT2007-278, 2007.

[6] Hagari, T., Ishida, K., Oda, T., Douura, Y., and Kinoshita, Y., "Heat Transfer and Pressure losses of W-shaped small ribs at High Reynolds Numbers for Combustor Liner," Journal of Engineering for Gas Turbines and Power, Vol. 133, 2011.

[7] Shevchuk, I., Jenkins, S., Weigand, B., von Wolfersdorf, J., Neumann, S., and Schnieder, M., "Validation and analysis of numerical results for a varying aspect ratio two-pass internal cooling channel," ASME Turbo Expo, Paper GT2008-51219, 2008.

[8] Schüler, M., Neumann, S. O., and Weigand, B., "Pressure Loss And Heat Transfer in a 180 Deg Bend of a Ribbed Two-Pass internal cooling channel with engine-simular cross sections, Part 1: Experimental Investigations," 8th European Conference on Turbomachinery, Fluid Dynamics and Thermodynamics, Paper ETC8-115, 2009.

[9] Taslim, M. E. and Spring, S. D., "Effects of turbulator profile and spacing on heat transfer and friction in a channel," Journal of Thermophysics and Heat Transfer, Vol. 8, 1994, pp. 555-562.

[10] Taslim, M. and Ren, B., "A Combined Numerical and Experimental Study of Heat Transfer in a Cooling Channel Roughened with 90 Ramped Ribs,” 2016.

[11] Rallabandi, A. P., Alkhamis, N., and Han, J. C., "Heat Transfer and Pressure Drop Measurements for a Square Channel With 45 deg Round-Edged Ribs at High Reynolds Numbers," Journal of Turbomachinery, Vol. 133, July 2011.

[12] Han, J., Ou, S., Park, J., and Lei, C., "Augmented heat transfer in rectangular channels of narrow aspect ratios with rib turbulators," International Journal of Heat and Mass Transfer, Vol. 32, No. 9, 1989, pp. 1619-1630. 
[13] Jackson, D., Ireland, P., and Cheong, B., "Combined Experimental and CFD study of HP Blade MultiPass Cooling System,” ASME Turbo Expo, Paper GT2009-60070, 2009.

[14] Huh, M., Liu, Y., liu, Y., and Han, J., "High Rotation Number Effect on Heat Transfer in a Rectangular (AR=2:1) Two-Pass Channel," ASME Journal of Heat Transfer, Vol. 133, 2011.

[15] Ryley, J., McGilvray, M., and Gillespie, D. R. H., "Stationary Internal Cooling Passage Experiments for an Engine Realistic Configuration," 10th European Conference on Turbomachinery, Fluid Dynamics and Thermodynamics, 2013.

[16] Ireland, P. T. and Jones, T. V., "Liquid crystal measurements of heat transfer and surface shear stress," Measurement Science Technology, 2000, pp. 969-986.

[17] Wang, Z., The Application of Thermochromic Liquid Crystals to Detailed Turbine Blade Cooling Measurements, DPhil Thesis, University of Oxford, 1991.

[18] Ireland, P. T., Internal Cooling of Turbine Blades, DPhil Thesis, University of Oxford, 1987.

[19] Shultz, D. L. and Jones, T. V., "Heat transfer measurements in short-duration hypersonic test facilities," AGARDograph 165, 1973.

[20] Ling, J. P., Ireland, P. T., and Turner, L., "A Technique for processing transient heat transfer, liquid crystal experiment in the presence of lateral conduction," ASME Turbo Expo, Paper GT2003-38446, 2003.

[21] Buttsworth, D. R. and Jones, T. V., "Technical note: Radial conduction effects in transient heat transfer experiments," Aeronautical Journal, Vol. 101, No. 1005, 1997, pp. 209-212.

[22] Kline, S. and McClintock, F. A., "Describing Uncertainties in Single-Sample Experiments," Mechanical Engineering, January 1953, pp. 3.

[23] McGilvray, M., Orozco Pieiro, C., Axe, T., Ryley, J., and Gillespie, D. R. H., "Comparison of Stationary Internal Cooling Passage Experimental Data to Numerical Simulations," 10th European Conference on Turbomachinery, Fluid Dynamics and Thermodynamics, 2013.

[24] Forsyth, P. R., McGilvray, M., and Gillespie, D. R. H., "Secondary Flow and Heat Transfer Coefficent Distributions in the Developing Flow Region of Ribbed Turbine Blade Cooling Passages," ASME Turbo Expo, Paper GT2014-26737, 2014. 